\title{
$\begin{array}{r}\text { WAGENINGEN } \\ \hline\end{array}$
}

\section{Can food choice be influenced by priming with food odours?}

Polet, I. A., Vingerhoeds, M. H., Perez-Cueto, F. J. A., \& de Wijk, R. A.

This is a "Post-Print" accepted manuscript, which has been published in "Food Quality and Preference"

This version is distributed under a non-commercial no derivatives Creative Commons (c) (1) $\Theta \Theta$

(CC-BY-NC-ND) user license, which permits use, distribution, and reproduction in any medium, provided the original work is properly cited and not used for commercial purposes. Further, the restriction applies that if you remix, transform, or build upon the material, you may not distribute the modified material.

Please cite this publication as follows:

Polet, I. A., Vingerhoeds, M. H., Perez-Cueto, F. J. A., \& de Wijk, R. A. (2018). Can food choice be influenced by priming with food odours? Food Quality and Preference, 66, 148-152. DOI: 10.1016/j.foodqual.2018.01.019

You can download the published version at:

https://doi.org/10.1016/j.foodqual.2018.01.019 


\section{Accepted Manuscript}

Short Communication

Can food choice be influenced by priming with cucumber or bread odour?

M.R. Mors, I.A. Polet, M.H. Vingerhoeds, F.J.A. Perez-Cueto, R.A. de Wijk

PII:

S0950-3293(18)30083-1

DOI:

https://doi.org/10.1016/j.foodqual.2018.01.019

Reference:

FQAP 3463

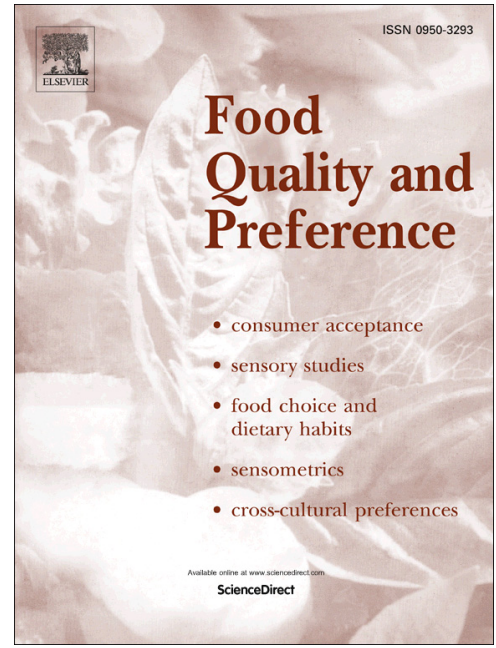

To appear in:

Food Quality and Preference

Received Date:

21 June 2017

Revised Date:

25 January 2018

Accepted Date:

29 January 2018

Please cite this article as: Mors, M.R., Polet, I.A., Vingerhoeds, M.H., Perez-Cueto, F.J.A., de Wijk, R.A., Can food choice be influenced by priming with cucumber or bread odour?, Food Quality and Preference (2018), doi: https:// doi.org/10.1016/j.foodqual.2018.01.019

This is a PDF file of an unedited manuscript that has been accepted for publication. As a service to our customers we are providing this early version of the manuscript. The manuscript will undergo copyediting, typesetting, and review of the resulting proof before it is published in its final form. Please note that during the production process errors may be discovered which could affect the content, and all legal disclaimers that apply to the journal pertain. 


\section{Can food choice be influenced by priming with cucumber or bread odour?}

M. R. Mors ${ }^{1,2}$, I. A. Polet ${ }^{1}$, M. H. Vingerhoeds ${ }^{1}$, F. J. A. Perez-Cueto ${ }^{2}$, R. A. de Wijk ${ }^{1}$

${ }^{1}$ Wageningen Food and Biobased Research, Wageningen, The Netherlands

${ }^{2}$ University of Copenhagen, Copenhagen, Denmark

Correspondence to be sent to: Wageningen Food and Biobased Research, René A. de Wijk, Consumer Science \& Health, P.O. Box 17, 6700 AA Wageningen, the Netherlands.

E-mail: rene.dewijk@wur.nl

Telephone: $+31(0) 317481309$

Keywords: Priming, Odour, Food choice, Real life 


\section{Abstract}

Recent research suggests that non-attentively perceived odours may significantly influence people's food choices. This study's aim was to examine the effects of different types of non-attentively perceived food odours, namely, bread odour and cucumber odour, on subsequent lunch choices in a real-life setting.

The study was conducted using a within-participant design ( $n=37$, age $21-55$ years). Participants took part in three sessions: two priming conditions (bread and cucumber odour) and one control condition (no odour). During each session, participants started by answering a questionnaire for 20 minutes, in a room in which they were exposed to one of the odour conditions. The questionnaire functioned as a 'lure' task. Subsequently, participants were guided to the restaurant where they could choose lunch from a buffet. Besides lunch choice, sociodemographic factors, personality traits, and eating behaviour factors were assessed.

Odour priming and control conditions did not affect lunch selections $\left(\chi^{2}(2, N=37)=28.1, p=0.46\right)$. Selfreported positive mood was significantly affected by odour condition $(F(2,72)=3.26, p=0.044)$. In conclusion, odour condition did affect mood but not lunch choice. It is therefore questionable whether an odour prime can be used as a nudge to contribute to healthy food choice behaviour. 


\section{Introduction}

Eating behaviour has a crucial effect on human health (Lobstein \& Millstone, 2007; Stroebele \& De Castro, 2004; Whitney \& Rolfes, 2008). Obesity, a risk factor for chronic disease (cardiovascular disease, Type 2 diabetes mellitus and cancer), results of a complex combination of energy dense food intake, poor diet quality, low physical activity that interplay with individual health, psychological and social wellbeing. Moreover, an "obesogenic" environment has made individual choices towards healthy foods more difficult. Therefore, evaluating ways to support improved eating behaviour is key. Moreover, factors related to specific food and eating environment are often changeable, especially those in the social and physical surroundings (e.g. Meiselman, 2006; Sobal, Bisogni, Devine, \& Jastran, 2006; Köster, 2009; Rozin, 2006). These factors include the presence of other people, sound, temperature, smell, light, food presentation, location, time, and distraction (Stroebele \& De Castro, 2004). Many studies show effects of these external factors on food choice and intake.

The present study investigates the effect on food choice of one particular type of external factor, namely ambient odours. More specifically, the ability of weak odours to prime subsequent food choices in a real-world environment was tested. To the best of our knowledge, only four studies have assessed the effect of odour priming with weak food odours on food choice (e.g. De Wijk \& Zijlstra 2012). Three of these four studies have shown that priming effects seem to be specific to the food cue (the food from which the odour originates) and the context of consumption of the food that is represented by the prime. 'Pain au chocolate' is a pastry mainly consumed in France for breakfast, as a dessert, or as a snack (Chambaron et al., 2015). Exposure to this sweet-fatty odour influenced food choices especially in the dessert category. Exposure to the odour of melon, which is mainly consumed as a starter in France, tended to modify choices of starters, but not those of other courses (Gaillet et al., 2013). With a melon odour present, participants were more likely to choose starters with vegetables, but not main courses or desserts with fruit and vegetables. The odour of pear, which is mainly consumed as a dessert in France, guided participants towards more fruity desserts, but not towards more starters or main courses containing vegetables (Gaillet et al., 2013, 2014).

Earlier research indicated a more general effect on food choice of odour priming with vanilla odour compared to priming with a citrus odour (De Wijk et al., 2010, unpublished results). In this study, participants were exposed to the odour only when they entered a buffet restaurant, in contrast to a 10- or 15-minute exposure in the other odour studies. Although it was expected that, after exposure to vanilla odour for example, more vanilla custard desserts would be chosen, in fact more participants selected a combination meal rather than separate meal components.

The aim of the present study was to examine the effects of two different weak food odours, bread and cucumber odour, on subsequent lunch choices in a real-life setting (Restaurant of the Future, Wageningen, The Netherlands). It was hypothesised that odour priming with bread odour would increase the choice of bread, and cucumber odour would increase the choice of salads and the like. If the observed effects are indeed specific to the food cue, these odour primes could be promising nudges for healthier food choices in real life. Moreover, contrary to the four studies discussed above, in the present study the effects of odour priming on lunch choice are researched in a more realistic and less controlled setting. A within subject design was chosen for the present study. In this way, individual differences could be taken into account. 


\section{Materials and methods}

\subsection{Participants}

Participants were recruited using the Wageningen Food \& Biobased Research panel database, through social media, and by distributing flyers. Participants were unaware of the real study purpose. They were told the study consisted of three sessions on different questionnaires regarding personality traits, concluded with an online questionnaire at home. Participants received free lunches up to a value of $€ 5$ (one after each test session) in the company restaurant and $€ 5$ on completion of the entire study. All participants signed consent forms on the first test day. The study protocol was approved by the Social Science Ethics Committee of Wageningen University.

Thirty-seven participants ( 32 females and 5 males) were selected based on availability and selection criteria. Participants had a self-reported normal ability to smell and taste and BMI between 18.5 and $30 \mathrm{~kg} / \mathrm{m}^{2}$, did not follow a specific diet, were competent in the Dutch language, not pregnant nor breastfeeding, did not smoke, and consumed on average no more than 21 alcoholic consumptions per week. Participants were asked to abstain from eating two hours before a test session, not to use strongly scented care products, and to take the scent of smoke in clothes into account.

\subsection{Test facilities}

The priming part of the study took place in two test rooms within the Restaurant of the Future, Wageningen, and The Netherlands. The rooms were identical in size, furniture, and (lack of) decoration. They were equipped with a vaporiser (Zaluti Multi Controller, AllSens, The Netherlands) and air conditioning to control ambient conditions. Room temperature was held at around $21^{\circ} \mathrm{C}$. Both rooms were used for four to five participants per test session. Per test day, the rooms were scented with bread odour, cucumber odour, or no odour (control), depending on the priming condition applied that day.

\subsection{Odour primes}

The odours used were bread (Bread flavour liquid sc513519, International Flavors \& Fragrances, The Netherlands) and cucumber (Cucumber flavour L-526060, Givaudan, The Netherlands). The vaporiser in each room was filled with the test odour or water (control condition). Clean air, generated by a programmable compressor, was fed through the saturated headspace of the aroma vessel into the room.

In pre-tests, the compressor settings and the pre-diluted concentrations required to produce the optimal, non-attentively perceived, odour intensities were determined in a small study setting with 11 participants not involved in the actual priming experiment. Bread odour was used in a dilution of $2 \% \mathrm{v} / \mathrm{v}$ in propylene glycol, with compressor settings on 8 pulses every 10 minutes. Cucumber odour was not diluted, with compressor settings on 6 pulses every 10 minutes. For the control condition, water was used with compressor settings on 7 pulses every 10 minutes. The compressor was activated 2.5 hours before the test session. Together with the room ventilation, this produced a relatively stable intensity during the sessions. Only one odour was used on each test day to ensure that odours would not mix in between sessions.

\subsection{Lunch choice}

The lunch choice part of the study took place in the company restaurant. Participants moved freely between buffets (setup see Figure 1). Each buffet table represented a different lunch category that 
was constant during the whole study. The specific assortment within each lunch category varied across days. Participants made their lunch choices from the available assortment.

FIGURE 1 ABOUT HERE

\subsection{Questionnaires during priming conditions}

Each session, participants completed different questionnaires on personality traits and ended with a puzzle with a neutral theme. Dutch versions of the following questionnaires were used: the Brief Self Control Measure (Tangney, Baumeister, \& Boone, 2004); the Barratt Impulsiveness Scale (Patton \& Stanford, 1995), the Mindful Attention Awareness Scale (Brown \& Ryan, 2003), the shortened 18item version of the Need for Cognition Scale (Cacioppo \& Petty, 1982). Each session participants' mood status was measured using the PANAS (Positive Affect and Negative Affect Schedule) questionnaire (Watson, Clark, \& Tellegen, 1988). Additional questionnaires on self-consciousness, maximising, regret, and individualism and collectivism were not analysed.

The questionnaires and puzzles functioned as a 'lure' task. After 20 minutes, participants were asked to stop their task. Data from the discussed personality tests and the mood tests were analysed.

\subsection{Procedure}

Table 1 shows the setup of the study. Participants were divided into six groups based on availability, age, sex, and BMI. Each group participated in three weekly sessions with a different order of priming conditions.

\section{TABLE 1 ABOUT HERE}

Each test session, participants filled in questionnaires for 20 minutes while being primed with the odour. They were not allowed to speak with one another. Afterwards they were accompanied to the restaurant. Participants were told their lunch was a compensation for filling in the questionnaires and it was refunded, with a maximum of $€ 5$, when handing in the receipt.

\subsection{Debriefing questionnaire}

After the last test session, participants received an online debriefing questionnaire on odour notification and identification during the study, perceived odour influence on their lunch choices, and educational level, nationality, work, and income. Furthermore, the Dutch Eating Behaviour Questionnaire (DEBQ) (van Strien, 2012) was included. Participants were informed about the real purpose of the study; all participants reconfirmed their participation.

\subsection{Data analyses}

Buffet tables represent lunch categories, which were constant over the entire study period. However, the specific assortment of each lunch category varied across days. Specific product choices were generalised to the broader lunch categories. The final lunch categories were: Bread, Dairy (Cold drinks), Juice (Cold drinks), Water (Cold drinks), Soda (Cold drinks), Yogurt with topping (Desserts), Fruit/Vegetable fresh juices, Fruit, Coffee (Hot drinks), Lunch salad, Salad bar, Sandwiches, Savoury sandwich filling, Snacks, Soups, Chocolate sandwich filling (Sweet s.f.), and Warm meal. For each lunch category, the total number of products that participants chose was recorded per odour condition. Non-parametric Chi-square analysis was used to verify significant effects of odour and 
control conditions on selection frequencies from lunch categories and on frequencies of odour awareness. Mood scores are analysed with a repeated measures ANOVA with mood scores as withinsubject repeated factor (IBM Corp. Released 2013. IBM SPSS Statistics for Windows, V 22.0. Armonk, NY: IBM Corp.).

\section{Results}

\subsection{Participants' characteristics}

Table 2 provides a description of the characteristics of the 37 participants. The mean age of the participants was 32 years $(S D=13.3$ ). Participants had a mean self-reported BMI of 22.7. On average, participants scored in the middle (around 50) for Self-control, Need for cognition, and Mindfulness. The mean score for impulsivity was a bit lower (34). The mean scores were average for Restrained eating, Emotional eating, and Clear emotions, and above average for External eating and Diffuse emotions. Most participants were either employed (15) or students (18), had an income of either less than $€ 500$ (13) or between $€ 500$ and $€ 3000$ (15), and had a higher level of education (31). All 37 participants were Dutch.

\section{TABLE 2 ABOUT HERE}

\subsection{Lunch choice}

Frequencies with which products from the lunch categories were selected are shown per condition in Table 3. Odour priming did not affect lunch selections $(\chi 2(2, N=37)=28.1, p=0.46)$.

\section{TABLE 3 ABOUT HERE}

\subsection{Odour awareness}

Data from the debriefing questionnaire showed that all participants were unaware of the real purpose of the study. The questions regarding whether the participants noticed an odour during the first, second, and/or third test session and which odour they smelled were divided into four score categories for each condition. Table 4 shows the frequencies of the scores for odour awareness for the three conditions. Chi square analysis verified no significant effect of odour priming on odour awareness scores $\left(\chi^{2}(2, N=37)=10.1, p=0.12\right)$.

\section{TABLE 4 ABOUT HERE}

\subsection{Mood}

The PANAS questionnaire was used to measure participants' positive and negative mood during each of the three conditions. Table 5 shows the average scores and standard deviations for positive and negative mood for the three conditions (the scores were normalised to scores on a scale of 0 to 100). Overall, positive mood was scored in the middle and negative mood was scored low. No significant within-subjects effect of condition was found for Negative $\operatorname{mood}(F(1.61,57.79)=2.09, p=0.142)$. A significant effect of condition was found for Positive $\operatorname{Mood}(F(2,72)=3.26, p=0.044)$. The paired 
comparisons showed that Positive Mood was significantly lower in the cucumber condition compared to the bread condition $(p=0.042)$.

\section{TABLE 5 ABOUT HERE}

\section{Discussion and conclusion}

\subsection{Discussion}

The objective of this study was to examine the effects of priming with a non-attentively perceived weak bread and cucumber odour on subsequent lunch choices in a real-life setting. A mechanism based on semantic priming of corresponding foods (Chambaron et al., 2015; Gaillet et al., 2013, 2014) would predict that for example bread would be chosen more often with bread odour and cucumber odour would increase the choice of salads and the like.

However, these results were not found in this study. Even though odours did affect other variables such as mood, no consistent effects of odours on food choice were observed. The fact that the odour effects on lunch choices in this study lack any apparent specificity suggest limited opportunities for odours to be used as nudges to facilitate healthier food choices. Obviously, more research is needed to better understand the mechanisms and to be able to tailor odours to specific consumption contexts and consumers (see also Bucher et al., 2016; Sunstein, 2016).

Reasons for our lack of consistent odour effects may include that odour effects do not follow a onesize-fits-all principle but may for example vary with personal characteristics such as autobiographical memories (Chambaron et al., 2015; Gaillet et al., 2013, 2014; Smeets \& Dijksterhuis, 2014). Different autobiographical memories may result in different odour-food associations. Consequently, odours that may facilitate specific food choices for some may not affect - or may even suppress - food choices for others.

The duration of odour exposure may play a role in the results that were found: it could be that the odours became satiating after a period of 20 minutes. Sensory-specific satiety is a phenomenon often seen when a person is eating food, resulting in a decreased pleasantness of the food eaten in comparison to foods that are not yet eaten (e.g. Rolls, Rolls, Rowe, \& Sweeney, 1981). However, even in a study that used attentively present odours this effect was not found (Ramaekers, Boesveldt, Lakemond, van Boekel, \& Luning, 2014). So it is unlikely that sensory-specific satiety played a role. Alternatively, the intensities used in this study may have been too low for non-attentive detection. The intensities were determined in a pre-test with different participants. The scores for odour awareness in the debriefing questionnaire showed that most participants were not aware of an odour during the priming conditions; this could indicate that the odour was non-attentively perceived by most participants, or it could indicate that the odour intensity was too low to be perceived at all. Moreover, recalling this information relies on the participants' ability to remember this, whereas the participants in the pre-test did not have to rely on memory.

One of the strong points of this study is that a more realistic setting is used (a buffet restaurant) than in most other studies. This makes the results more translatable and applicable to real-life situations where consumers face countless food-related cues. Most other studies found an effect of odour priming when participants were conducted in a more or less controlled setting with a limited number of food options. In the present real-life study with many more food options, smaller and less specific 
effects are observed. However, there were also some limitations to this setting. First of all, the specific assortment varied every day. This made it hard to analyse the results in more detail. It was only possible to look at the more general lunch categories, whereas priming could have affected specific products. In addition, food preferences or liking of the dishes could have played a role and the fact that participants might tend to vary their lunch choice across the three test days because they wanted to try something different. Also, participants were probably exposed to interfering odours when walking from the mood room to the restaurant and in the restaurant itself. This could have minimised or altered the odour priming effects.

\subsection{Conclusions}

No effects of odour primes on food choice in a real-life setting were observed. Therefore, it is questionable whether these non-attentively perceived odour primes could be used as a nudge to contribute to healthy food choice behaviour. Additionally, this study points towards topics of interest to better understand odour priming on food choice, namely the role of odour awareness, the role of appetite, and the methodology of odour priming studies. 


\section{Acknowledgements}

We thank the participants in this study. In addition, we thank Mariska Nijenhuis-de Vries, Milou Vrijhof, Canan Ziylan, Moniek van Waaijenburg, Berber Dorhout, and Sanne van Mourik for their help in carrying out the study, Ivo van de Lans for his suggestions on the data analysis, and Catherine O'Dea for improving the use of English. 


\section{References}

Brown, K. W., \& Ryan, R. M. (2003). The benefits of being present: Mindfulness and its role in psychological well-being. Journal of Personality and Social Psychology, 84(4), 822-848.

Bucher, T., Collins, C., Rollo, M. E., McCaffrey, T. A., de Vlieger, N., van der Bend, D., Truby, H., PerezCueto, F. J. (2016). Nudging consumers towards healthier choices: A systematic review of positional influences on food choice. British Journal of Nutrition, 115(12), 2252-2263.

Cacioppo, J. T., \& Petty, R. E. (1982). The need for cognition. Journal of Personality and Social Psychology, 42(1), 116-131.

Chambaron, S., Chisin, Q., Chabanet, C., Issanchou, S., \& Brand, G. (2015). Impact of olfactory and auditory priming on the attraction to foods with high energy density. Appetite, 95, 74-80.

de Wijk, R.A., Zijlstra, S. (2012). Differential effects of exposure to ambient vanilla and citrus aromas on mood, arousal and food choice. Flavour, 1:24.

Gaillet, M., Sulmont-Rossé, C., Issanchou, S., Chabanet, C., \& Chambaron, S. (2013). Priming effects of an olfactory food cue on subsequent food-related behaviour. Food Quality and Preference, 30(2), 274-281.

Gaillet, M., Sulmont-Rossé, C., Issanchou, S., Chabanet, C., \& Chambaron, S. (2014). Impact of a nonattentively perceived odour on subsequent food choices. Appetite, 76, 17-22.

Köster, E. P. (2009). Diversity in the determinants of food choice: A psychological perspective. Food Quality and Preference, 20(2), 70-82.

Lobstein, T., \& Millstone, E. (2007). Context for the PorGrow study: Europe's obesity crisis. Obesity Reviews, 8(s2), 7-16.

Meiselman, H. L. (2006). The role of context in food choice, food acceptance and food consumption. In R. Shepherd \& M. Raats (Eds.), The psychology of food choice (Vol. 3, pp. 179-199). Wallingford: CABI.

Patton, J. H., \& Stanford, M. S. (1995). Factor structure of the Barratt impulsiveness scale. Journal of Clinical Psychology, 51(6), 768-774.

Ramaekers, M. G., Boesveldt, S., Lakemond, C. M. M., van Boekel, M. A. J. S., \& Luning, P. A. (2014). Odors: Appetizing or satiating? Development of appetite during odor exposure over time. International Journal of Obesity, 38(5), 650-656.

Rolls, B. J., Rolls, E. T., Rowe, E. A., \& Sweeney, K. (1981). Sensory specific satiety in man. Physiology \& Behavior, 27(1), 137-142.

Rozin, P. (2006). The integration of biological, social, cultural and psychological influences on food choice. In R. Shepherd \& M. Raats (Eds.), The psychology of food choice (Vol. 3, pp. 19-39). Wallingford: $\mathrm{CABI}$.

Smeets, M. A. M., \& Dijksterhuis, G. B. (2014). Smelly primes-when olfactory primes do or do not work. Frontiers in Psychology, 5. doi: 10.3389/fpsyg.2014.00096.

Sobal, J., Bisogni, C. A., Devine, C. M., \& Jastran, M. (2006). A conceptual model of the food choice process over the life course. In R. Shepherd \& M. Raats (Eds.), The psychology of food choice (Vol. 3, pp. 1-18). Wallingford: CABI.

Stroebele, N., \& De Castro, J. M. (2004). Effect of ambience on food intake and food choice. Nutrition, 20(9), 821-838. 
Sunstein, C. R. (2016). Nudges that fail. Available at SSRN: https://ssrn.com/abstract=2809658 or http://dx.doi.org/10.2139/ssrn.2809658.

Tangney, J. P., Baumeister, R. F., \& Boone, A. L. (2004). High self-control predicts good adjustment, less pathology, better grades, and interpersonal success. Journal of Personality, 72(2), 271324.

van Strien, T. (2012). Nederlandse vragenlijst voor eetgedrag - Handleiding. Amsterdam: Hogrefe.

Watson, D., Clark, L. A., \& Tellegen, A. (1988). Development and validation of brief measures of positive and negative affect: The PANAS scales. Journal of Personality and Social Psychology, 54(6), 1063-1070.

Whitney, E., \& Rolfes, S. R. (2008). Understanding nutrition (12 ed.). Wadsworth: Cengage Learning. 


\section{Figure legends}

Figure 1: lay-out of the buffets in the restaurant. 


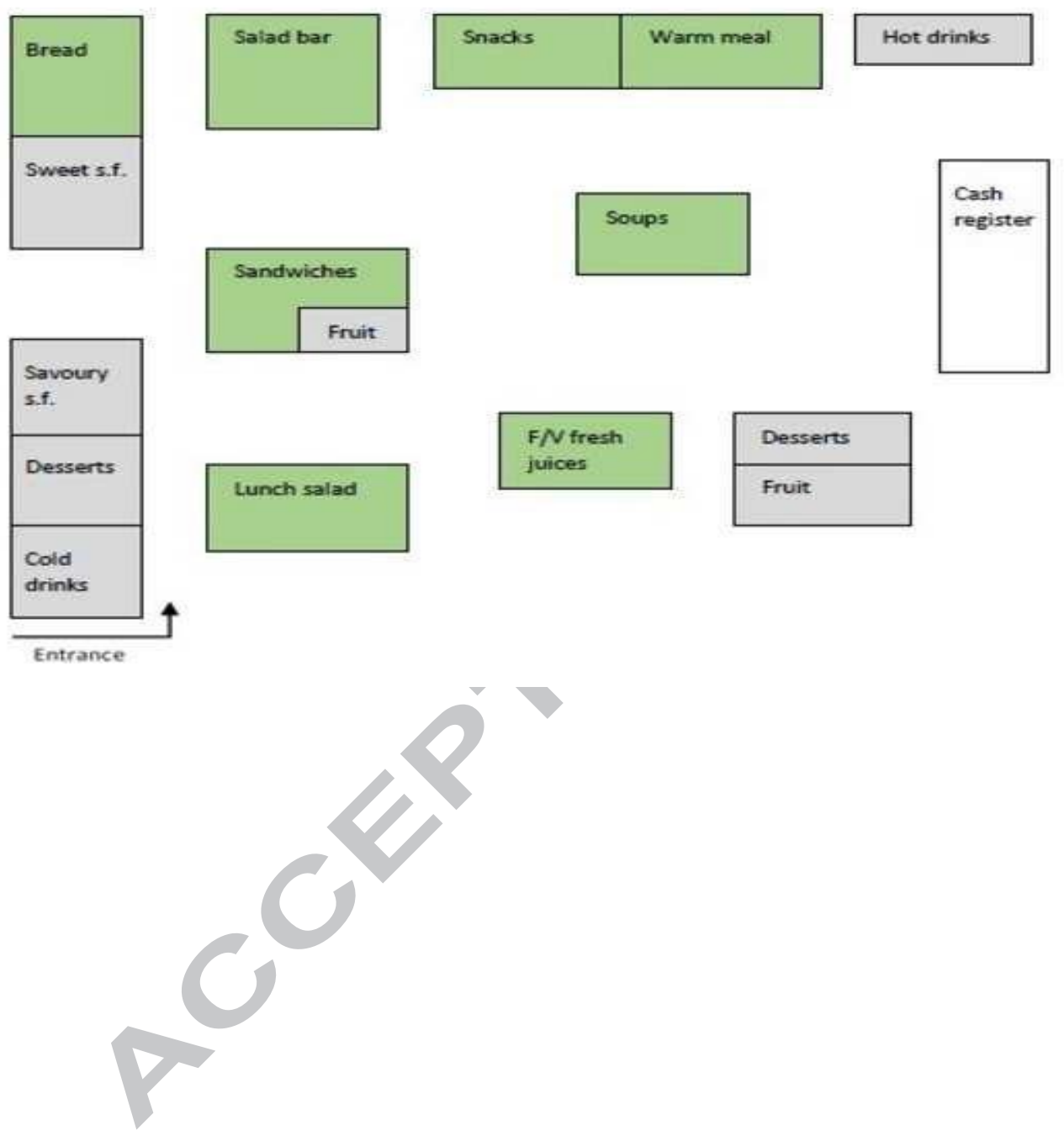


Table 1. Schedule of the test sessions, with six groups and three conditions: bread odour, cucumber odour, and no odour (control). The number of participants in each group is given in brackets.

\begin{tabular}{lllll}
\hline & & Tuesday & Wednesday & Thursday \\
\hline Week 1 & $11.30-12.00$ & Group A1: bread (6) & Group C1: control (5) & Group E1: cucumber (5) \\
& $12.15-12.45$ & Group B1: bread (6) & Group D1: control (6) & Group F1: cucumber (9) \\
& & & & \\
Week 2 & $11.30-12.00$ & Group A2: control (6) & Group C2: cucumber (4) & Group E2: bread (6) \\
& $12.15-12.45$ & Group B2: control (6) & Group D2: cucumber (7) & Group F2: bread (8) \\
& & & & \\
Week 3 & $11.30-12.00$ & Group A3: cucumber (6) & Group C3: bread (3) * & Group E3: control (6) \\
& $12.15-12.45$ & Group B3: cucumber (6) & Group D3: bread (6) & Group F3: control (8)
\end{tabular}

* Two participants participated on a Friday instead of a Wednesday from 11.30-12.00 in Week 3.

\# One participant switched from the first to the second group of that day

Table 2. Description of the characteristics of the 37 participants.

$\begin{array}{llllll}\text { Mean } & \text { Std. dev. } & \text { Min } & \text { Max } & \text { Freq. } & \%\end{array}$




\begin{tabular}{|c|c|c|c|c|c|c|c|}
\hline Age & 32 & 13.3 & 21 & 55 & Work & & \\
\hline BMI (self-reported) & 22.7 & 2.5 & 18.1 & 28.7 & Employed & 15 & 40.5 \\
\hline Self-control $^{1}$ & 53 & 15.3 & 32 & 81 & Student & 18 & 48.7 \\
\hline Impulsivity $^{1}$ & 34 & 10.0 & 19 & 54 & Unemployed & 4 & 10.8 \\
\hline Need for cognition ${ }^{1}$ & 59 & 14.0 & 30 & 88 & Income per month & & \\
\hline Mindfulness $^{1}$ & 56 & 12.4 & 32 & 80 & Less than $€ 500$ & 13 & 35.1 \\
\hline Restrained eating ${ }^{2}$ & 4 & 1.4 & 2 & 7 & $€ 500$ to $€ 3000$ & 15 & 40.5 \\
\hline External eating $^{2}$ & 5 & 1.1 & 3 & 7 & More than $€ 3000$ & 1 & 2.7 \\
\hline Emotional eating $^{2}$ & 4 & 1.31 .3 & 2 & 7 & Did not say & 8 & 21.6 \\
\hline Clear emotions & 4 & 1.3 & 2 & 7 & Education (initiated) & & \\
\hline \multirow[t]{7}{*}{ Diffuse emotions } & 5 & & 2 & 7 & Lower level & & 16.2 \\
\hline & & & & & Higher level & 21 & 83.8 \\
\hline & & & & & Nationality & & \\
\hline & & & & & Dutch & 37 & 100.0 \\
\hline & & & & & Sex & & \\
\hline & & & & & Female & 32 & 86.5 \\
\hline & & & & & & 5 & 13.5 \\
\hline
\end{tabular}

On a scale from 0 to 100 , where $0=l o w$ and $100=$ high .

On a scale from 1 to 7, where 1=very low, 2=low, 3=below average, 4=average, 5=above average, $6=h i g h$, and $7=v e r y$ high . 
Table 3. The total number of chosen products for each specific lunch category is shown per condition.

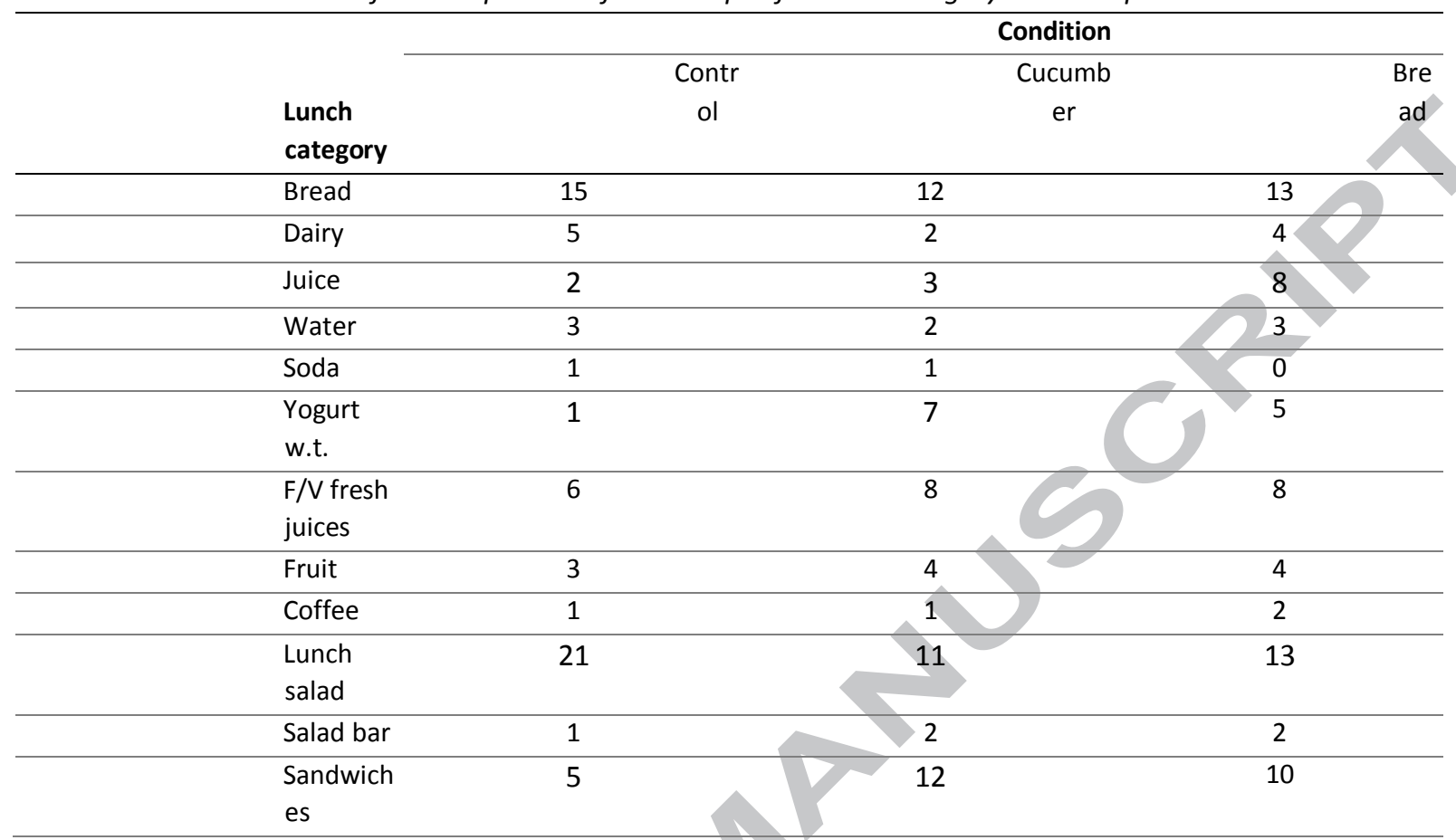




\begin{tabular}{lcccc}
$\begin{array}{l}\text { Savoury } \\
\text { s.f. }\end{array}$ & 15 & 8 & 6 \\
\hline Snacks & 3 & 2 & 6 \\
\hline Soups & 15 & 17 & 0 \\
\hline $\begin{array}{l}\text { Chocolate } \\
\text { s.f. }\end{array}$ & 1 & 0 & 4 \\
\hline Warm & 2 & 5 & 0 \\
\hline
\end{tabular}

Table 4. Frequencies of the scores for odour awareness for the three conditions.

\begin{tabular}{lrrrrrr}
\hline & \multicolumn{5}{c}{$\begin{array}{c}\text { Condition } \\
\text { Odour awareness }\end{array}$} & \multicolumn{3}{c}{$\begin{array}{c}\text { Cucumber } \\
\text { Freq. }\end{array}$} & \% & Freq. & \% & Bread & Freq. & $\%$ \\
\hline Not aware & 35 & 94.6 & 32 & 86.5 & 33 & 89.2 \\
Yes, but odour unknown & 0 & 0.0 & 0 & 0.0 & 2 & 5.4 \\
Yes, but wrong odour & 2 & 5.4 & 2 & 5.4 & 2 & 5.4 \\
Yes, right odour & 0 & 0.0 & 3 & 8.1 & 0 & 0.0 \\
\hline
\end{tabular}

Table 5. The average scores and standard deviation for Positive and Negative mood for the three conditions. 
Mood is visualised on a scale from 0 to 100, where $0=$ low score and 100=high score.

\begin{tabular}{lrrrrrr}
\hline & \multicolumn{5}{c}{$\begin{array}{c}\text { Condition } \\
\text { Control }\end{array}$} & \multicolumn{2}{c}{ Cucumber } & \multicolumn{2}{c}{ Bread } \\
\cline { 5 - 7 } Mood & Mean & Std. dev. & Mean & Std. dev. & Mean & Std. dev. \\
\hline Positive & 44 & 19.4 & 41 & 20.0 & 48 & 17.0 \\
Negative & 5 & 9.3 & 8 & 10.2 & 6 & 7.0 \\
\hline
\end{tabular}




\section{Highlights}

- Odour priming effects on food choice in a real-life setting are examined

- Non-attentively perceived bread and cucumber odour are used as odour primes

- Odours affected mood but not food choice

- Questionable whether an odour prime can be used as a nudge to affect food choices 